THYMIC TRACIIEOSTENOSIS AND THYMUS DEA'TH, WI'T REPOR'T OF CASES *

ANIJIR: CROT'II, M.D.

Surgeon to Grant IIospital aud Chlldren's IJospital colvmbus, ollo

To the five cases of thymus hyperplasia which I have reported, ${ }^{1}$ I wish to add two others. In the following discussion, I shall.refer sometimes to the cases previously reported.

\section{REPORT OF CASES}

CAse 6.-Miss B. M., nged 4l, suffering from an advanced exophthalmic goiter for three years, was extremely emaciated and lad a marked exophthalmos. Stellwag, Graefe and Moebius symptoms were present. Pulse-rate was 88 and extrenely irregular. Many of the heart-beats were not transnitted to the radial artery. The heart was enlarged. The enlargement of the thyroid gland affected both lobes and the isthmus. The right lobe was larger than the left, was irregular in surface and very hard in consistency. The inferior pole of the right lobe extended partly behind the sternum. Intense vascular symptoms, thrill and systolic murmur were present over the thyroid gland and in both supraclavicular spaces. Percussion showed a marked dulness over the sternum, extending about $2 \mathrm{~cm}$. beyond each sternal edge, and fusing below with the aren of cardiac dulness; no sonority between this dulness and the cardinc dulness. There were numerous ganglions along the carotid on both sides. Tremor was present. Perspiration was profuse.

The blood-examination revealed the following:

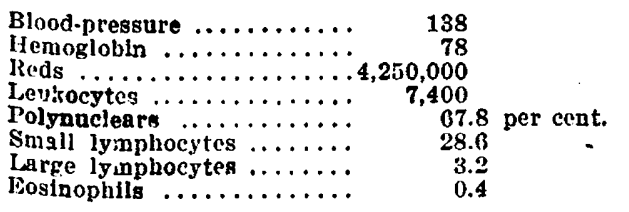

Diagnosis, advanced exophthalmic goiter with probible thymus hyperplasia.

Patient was kept in the hospital for medical treatment and rest. for two weeks and she improved so much that she seemed in good condition to stand a pole ligation. Ligation was performed on both superior poles under local nnesthesia. During the operation, the patient complained greatly of pain and asked for a few drops of ether, which were given. Operation lasted twenty minutes. During operation, she showed a general tremor, as if shivering from cold. While the suture of the skin was being made, patient had a collapse. Pupils became dilated, patient made six prolonged inspirations and then pulse stopped. She was dead. Oxygen, massage of the heart, intravenous transfusion were useless.

Necropsy.-Lungs were normal, no thrombosis in the pulmonary vein. In the superior anterior part of the mediastinal space, an enormous thymus was present, composed of three lolses; both lateral lobes covering entirely the anterior surface of the pericardium (Fig. 1), the left lobe measuring about 11 by $6 \mathrm{~cm}$; the right lobe 13 by 7 ; the middle lobe 4 by $2 \mathrm{~cm}$. The maximum of thickness in places was $2 \mathrm{~cm}$. The thymus gland was not weighed because it was left in situ. The thyroidea ima veins were very large. They formed two different trunks. The lymphatic glands on both sides of the neck were highly developed, being small, round and hard. The thyroid gland showed in its capsule large and numerous blood.

* Rrad before the Columbus Academy of Medicine, Oct. 14, 1912 1. Ciotti, Andie: The lRoentgen lay in Intrathoracic Golter and Thymus Hyperplasia, 'THe JounNaL A. M. A., Jan. 11. 1013, D. 117. vessels. It had the form and size deseribed in the physical examination. The heart was larger than normally. The right chamber was slightly enlarged, but neither chamber contained blood. The heart seemed to be eontracted. The thickness of the wall of the left ventricle was $2.5 \mathrm{~cm}$. The thickness of the wall of the right ventricle was $0.5 \mathrm{~cm}$. Trachea was not com. pressed. The abdomen showed nothing special. Microscopic examination of the thymus sliowed nothing of importance.

CASE 7.-July 10, 1912. Female baby, 7.5 pounds, delivered by Dr. Rogers, with forceps. 'The babe required no efforts at resuscitation, breathing at once and crying lustily and was apparently normal and treated as such. The ordinary cyanosis at birth was present and passed of in the ordinary period of a few minutes' time.

At $2 \mathrm{p} . \mathrm{m}$. the baby had what was described by the nurse as a choking spell. It turned blue, seemed to have difficulty in getting its breath, and gasped for breath. This spell yielded to the ordinary treatment of the nurse for cardiac and respiratory failure, namely, suspension by the feet, flagellation of the buttocks and splasing of cold water over the bare thorax and body. This attack lasted only a few moments and the babe again appeared to be all right, and was placed in the nursery with the other babies. About 8 p. m. a second attack occurred, more profound and serious; baby again turned blue, gasped for breath and "monned" as the nurse said, in a peculiar way, heard only once before in her experience, in the case of a baly that died a few hours after birth from the so-called persistent patent-foramen ovale. A whistling sound on both inspiration and expiration grew fainter and fainter, and in spite of efforts at resuscitation the baby died. This attack lasted about fifteen minutes.

Percussion of the thorax showed a dulness over the manubrium sterni, fusing downward with the cardiac dulness. It extended $2 \mathrm{~cm}$. beyond the left sternal edge and $2.6 \mathrm{~cm}$. beyond the right sternal edge (Fig. 2). The heart dulness extended downward to the sixth intercostal space, $0.5 \mathrm{~cm}$. from the right sternal edge and $0.5 \mathrm{~cm}$. from the nipple. Above the episternal notch no resistance was felt. 
The opening of the thorax showed that the outlines made by percussion were exact. There was an enormous thymus loented between the heart and the thyroid gland. The thymus occupied the entire uper part of the mediastinal space (Fig. 3). It was more developed toward the right side and presised the heart downward and the pulmonary rein, aorta and superior vena enva strongly backward against the spinal column. The division of the thymus into its two lobes was not apparent; it formed a uniform mass having a transversia diameter of $5 \mathrm{~cm}$., and measured $4.5 \mathrm{~cm}$. in length and $2.5 \mathrm{~cm}$. in thickness. After dissection, the windpipe was found compressed and flattened in the thoracic portion between the bruchiocephalic trunk and the left common carotid. Section of the heart slowed a patent foramen ovale with a semiluma membrane closing, in greater part, this formmen.

Denth in this case was certainly due to an abmormal enlargement of the thymus. The partly patent foramen ovale does not explain this sudden deatl, because the child was all right before and between the dyspneic spells; the color of the buby was absolutely normal and there was no difficulty in breathing

\section{THYMUS HYPERTLASIA IN CHILDREN}

In children what might be termed a latent thymus hyperplasia may exist for a longer or shorter period of time. Such eases do not come, as a rule, under surgical jurisdiction. 'They are seen by the fumily physician, who finds the child in poor general condition and suffering from some vague respiratory symptoms. 'The physician may or may not connect these symptoms with thymus hyperplasia; but even if he makes a correct diagnosis, the parents will never consider an operation until more decided dyspneic symptoms are present. Sometimes sudden deatl is the first synıtom which reveals this latent form of thymus hyperplasia, and in the majority of cases this condition is revealed only at the autopsy. To-day, as we know a little more of this pathologic condition, I belicve that this fulminating form of death without any prodromic symptoms is rare. As a rule the learned physician will find in the history of the case a few symptoms which will reveal the presence of the hyperplastic thymus. As in Bright's disease, there are in thymus hyperplasia some "minor symptoms" which will lead the physician to a correct diagnosis, and it is because such symptoms have not been carefully observed that the diagnosis of thymus hyperplasia is not made; as a result, the child is found dead in his bed. The autopsy shows a large thymus compressing the windpipe.

Certain cases of asphyxia of new-born babies are explained only by thymus hyperplasia. The child is born apparently dead and it often takes quite a long time to reanimate it; its breathing is difficult and loud. It renıins cyanotic and in many instances dies after a few minutes or hours. The autopsy shows only some asphyxial lesions and an enormous thymus displacing and compressing the windpipe-no cardiac malformations, no cerebral hemorrhage, possibly only a few subpleural and subpericardiac hemorrhages.

The most striking symptom of thymus hyperplasia is dyspnea. This may be characterized by only a labored respiration or by the most intense choking spell. Between these two extremes, all forms of transition are found. Dyspnea may be constant or intermittent, with or without acute paroxysms. Between attacks, respiration may be entirely normal. 'There may be a constant and persistent inspiratory stridor, and in extreme dyspnea an expiratory stridor also, which is, however, less marked. In paroxysmic dyspnea, the child suddenly suffocates and becomes cyanotic. The stridor is extremely marked, respiration becomes accelerated and there is a sucking in of the suprasternal and infrasternal fossac. 'The choking spell may occur without canse, or when the child cries from pain or anger. Hyperextension of the head or dorsal decubitus exaggerates dyspnea. This would explain why dyspmea is more marked during sleep than during waking hours.

These paroxysms of dyspnea are extremely alarming to witness, and there is a great temptation to perform a tracheotomy. In such cases tracheotomy is useless, because the tube used is too short, the pressure taking place lower down in the thorax. From now on, every tracheotomy outfit should have tracheotomy tubes long enough to reach the bifurcation of the trachea. An interesting lact of the thymic dyspnea is that the voice is normal during the paroxysms as well as between. The choking spell may last a few minutes, a few hours or a few days, and then respiration becomes normal aguin. In other cases, death ensues. In certain cases the child dies at the beginning of the choking spell.

This dyspneic condition begins, as a rule, in the first weeks or months and diminishes the second year of life and is more seldom found after this period. This may be due to the fact that the gland normally retrocedes after the second year of life and that the superior opening of the thorax becomes larger with the growth of the child.

The spell of suffocation is due to compression of the windpipe by the thymus hyperplasia. The trachea is compressed to a more or less marked degree; the posterior wall of the trachea comes in contact with the anterior, so that there is very little or no space at all for the passage of air. 'The trachea may be compressed and displaced at the same time, especially toward the right side. When the trachea has been released from the pressure of the thymus, the flattening may remain; but in certain cases, especially in younger children in whom the trachea has kept its normal elasticity, the trachea resumes its normal caliber. This is especially true in chronic and in intermittent cases.

Pressure on the windpipe by the thymus takes place at two different points (Fig. 5).

The first point of pressure is found between the posterior surface of the manubrium sterni and the first and second vertebrae. At the superior opening of the thorax of a child the anteroposterior diameter measures only $2 \mathrm{~cm}$, and as a rule the hyperplastic thymus measures more than $2 \mathrm{~cm}$. in thickness; as the superior opening of the thorax is absolutely rigid and cannot increase its diameter, the thymus coming up like a wedge between the sternum and the spinal column will naturally compress the windpipe. A finger placed behind the episternal notch feels the impact of the rising thymus. If the superior opening of the thorax cannot increase its diameter, it can, on the other hand, diminish it, for instance, in the hyperextension of the head (Fig. 6). In such cases the vertebrae are projected forward and in so doing. diminish the anteroposterior diameter of the superior opening of the thorax. This would explain why in certain cases death has followed such a position.

Another point at which the compression of the windpipe may take place, too, especially in adults, is the point situated between the brachiocephalic trunk and the left common carotid. This compression is not confined to one ring of the. trachea alone, but extends over a certain portion of it. This is easily understood when we consider the anatomic relations of the thymus with the trachea in that region. As the thymus presses on the anterior surface of the trachea in the space between the left common carotid and the brachiocephalic trunk, and as the trachea lies in front of the spinal column, in 


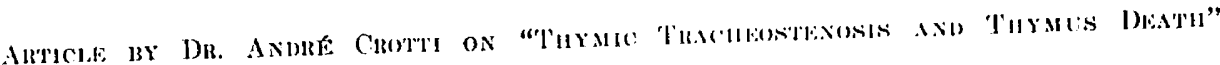

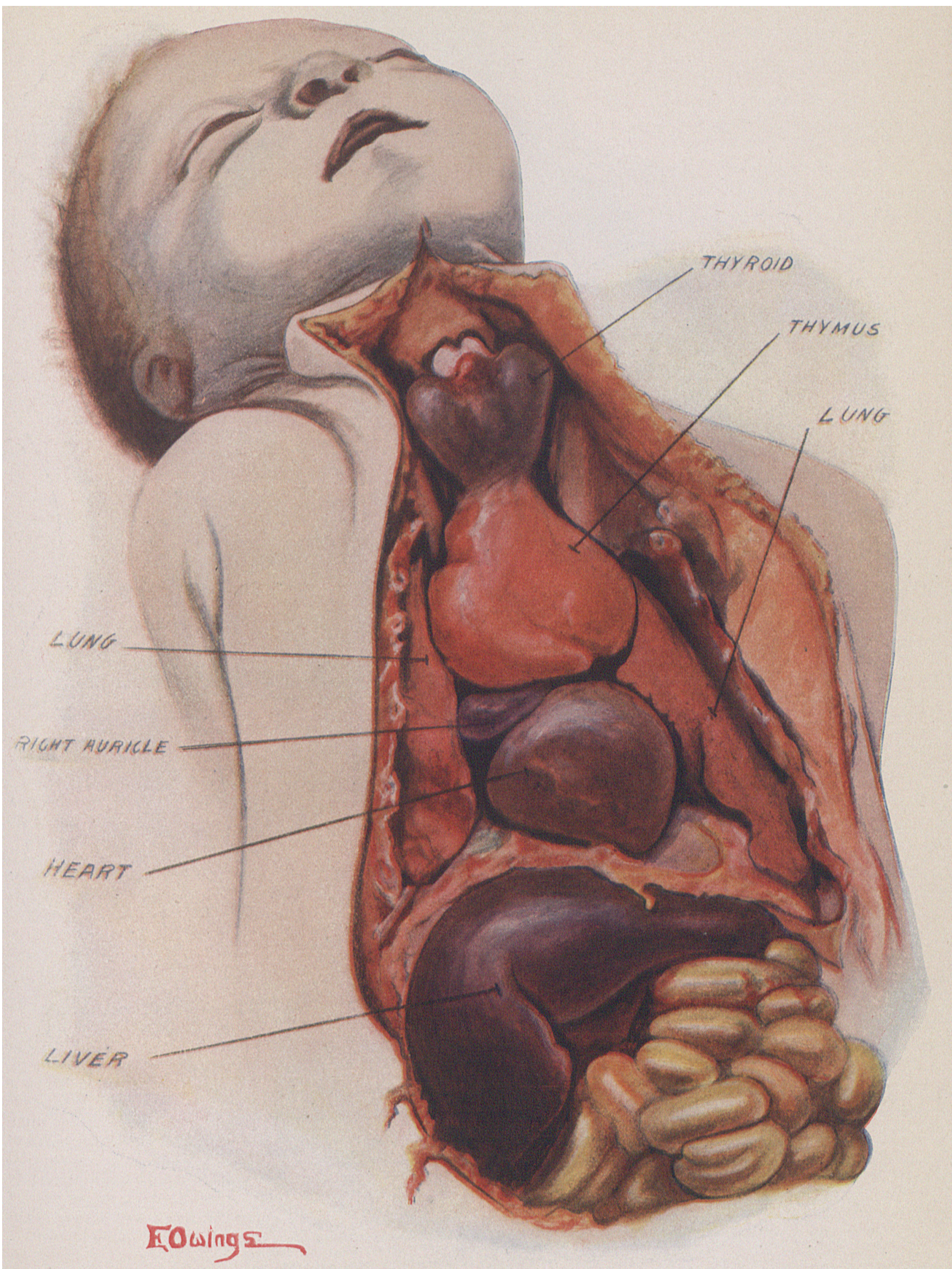

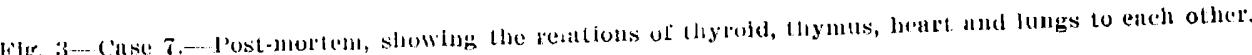

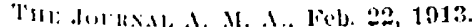




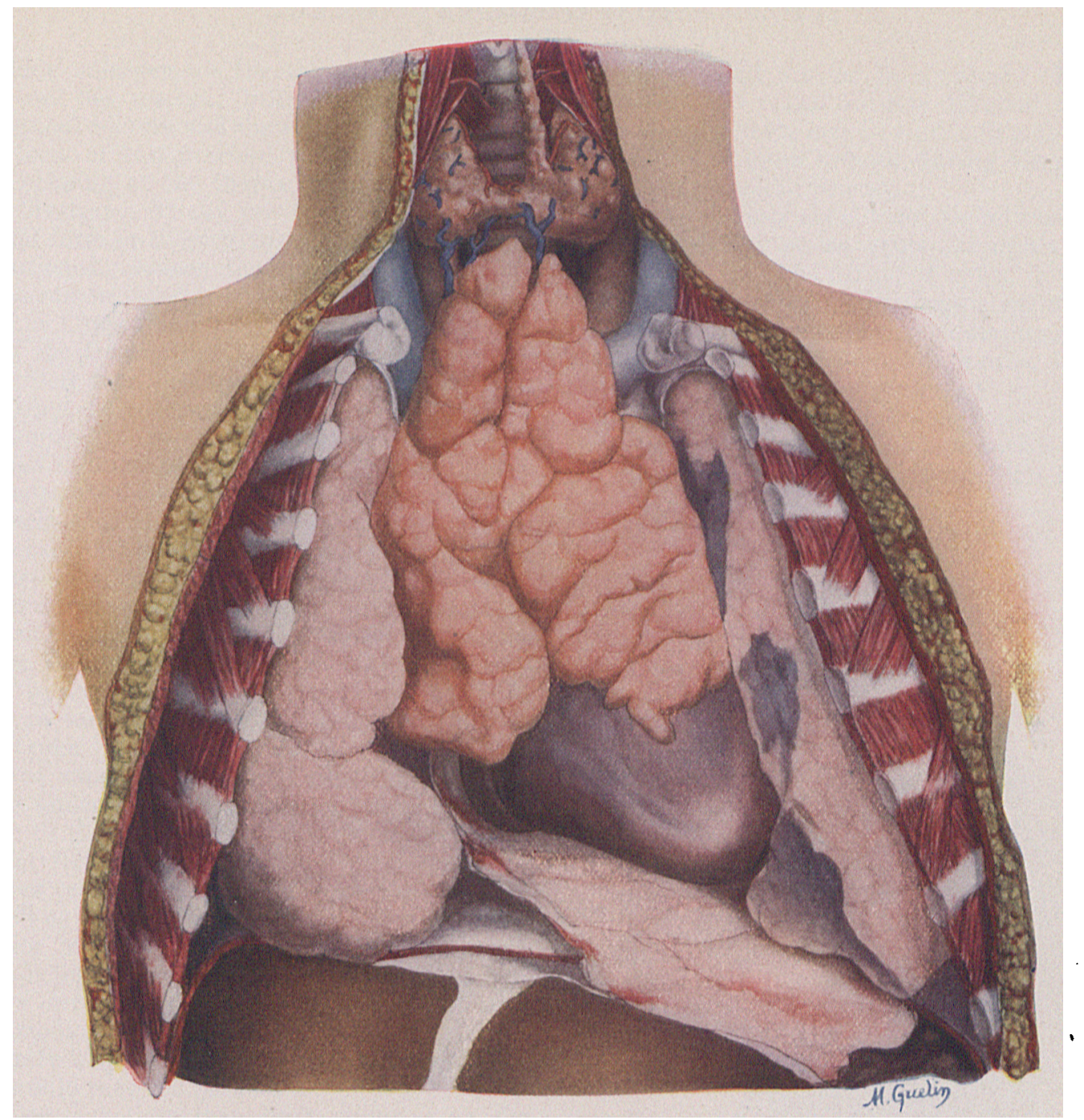

Fig. 4.--Hyperplastie thymus, showing its relations will the medlastimnl orgnns.

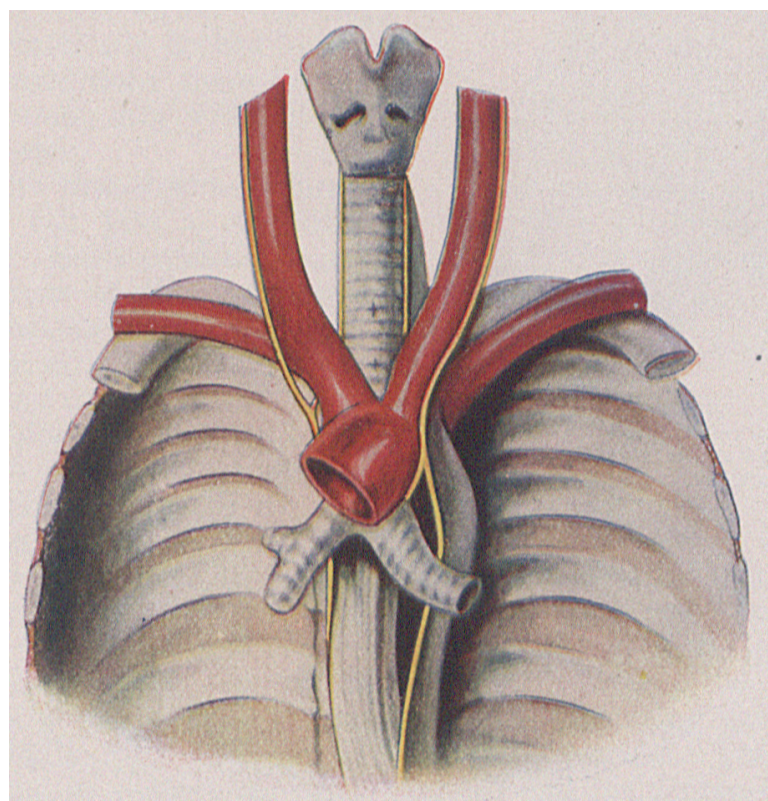

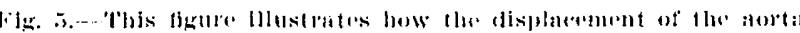

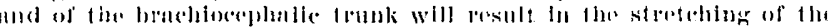

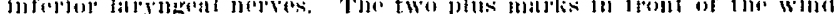

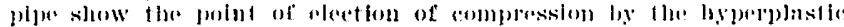
thymus (klosio).

'He: Joursal, A. M. A., Fol, 22, 1913 
eases of sudden enlargement the thymus will exert a compression on the trachea, being itself compressed between the spinal columm and the sternum.

The first form of compression, which takes place at the superior opening of the thorax, is found mostly in children, as illustrated by my previously reported Case 5. 'The second form or thoracie form, which takes place, as above mentioned, between the brachiocephalic trunk and the left common carotid, is found mostly in adults, as illustrated by Cases 1 and 3 .

Stenosis of the trachea lue to direct pressure by the thymus lias often been demonstrated at autopsies, and the cases which I have reported corroborate these findings. The successful surgical operations which have been peiformed in order to relieve patients of symptoms of thymic tracheostenosis also confirm these views. In a case of tracheostenosis Jackson was able to demonstrate by tracheoscopy that the trachea was compressed between the second and fourth ribs.

Such a compression is not present in all cases in which the patient dies with marked dyspneic symptoms. In these cases $I$ think the explanation may be the following: The hyperplastic thymus compresses and displaces the large vessels, namely, the aorta and the brachiocephalic trunk. If we remember that the inferior laryngeal nerve winds around these vessels (Fig. 5) it will easily be understood that these nerves will be put on the stretch by the displacement of these blood-vessels. We know that irritation or stretching of the inferior laryngeal nerve causes a spasm of the glottis, although dilators as well as constrictors of the glottis are supplied by the inferior laryngeal nerve. But the constrictors of the glottis being stronger than the dilators, the irritation of the inferior laryngeal nerve by stretching causes a spasmodic contraction, instead of a dilatation, and consequently a spasm of the glottis. In such cases tracheotomy would save the patient.

In other cases I believe that direct pressure on the base of the heart and consequently on the heart ganglions may be the cause of death. This explanation is suggested to me by Case 2, of my first series. In that case the base of the heart was practically choked by the enlarged thymus. In similar conditions there are no periods of choking, and the patient dies with all the symptoms of sudden cardiac collapse.

It would be a mistake to believe that thymus enlargenient is the only cause which can give a congenital stridor and respiratory trouble. Such conditions may also be found with malformations of the vestibulum of the larynx, with tracheobronchial glands and with adenoids. An accurate differential diagnosis must be made between these different forms of stridor.

The congenital vestibular stridor is seen after birth. It is entirely inspiratory and is not found on expiration, except in rare cases. Cyanosis is present too, but the stridor and dyspneic symptoms disappear with intubation of the larynx, which is not the case for the thymic dyspnea in children. The laryngoscopic examination, when possible, and the autopsy show that this stridor is due to a malformation of the superior opening of the larynx. The epiglottis has a gutter or beak-like form and is folded in the middle line. The plicae aryepiglotticae of both sides come in costact one with the other; they are pulled down over the opening of the Jarynx and so diminish its orifice; hence dyspnea and stridor.

Stridor due to tracheobronchial glands is found mostly on expiration, and the voice has a bitonal character. Furthermore, the thymic stridor is congenital; the tracheobronchial stridor is acquired. Pereussion and radioscopy will reveal entirely different findings.

In arlenoids there may be a difficult and labored breathing. which is more noticed during sleep; but in such cases, diagnosis will be easy.

'Thymic stenosis should not be mistaken for a retrovertebral aloscess or an acute laryngitis. In laryngospasm of infancy the period of apnea is very short, and in a lew seconds respiration begins again. It is always a manifestation of a spasmogene diathesis and is always accompanied by other symptoms or other stigmata (Hrib's facial and I'rousseau symptoms).

The lyperplastic thymus mav come in contact with and compress the right and left amricle and ventricle, the superior vena cava, the aorta, the brachiocephalic

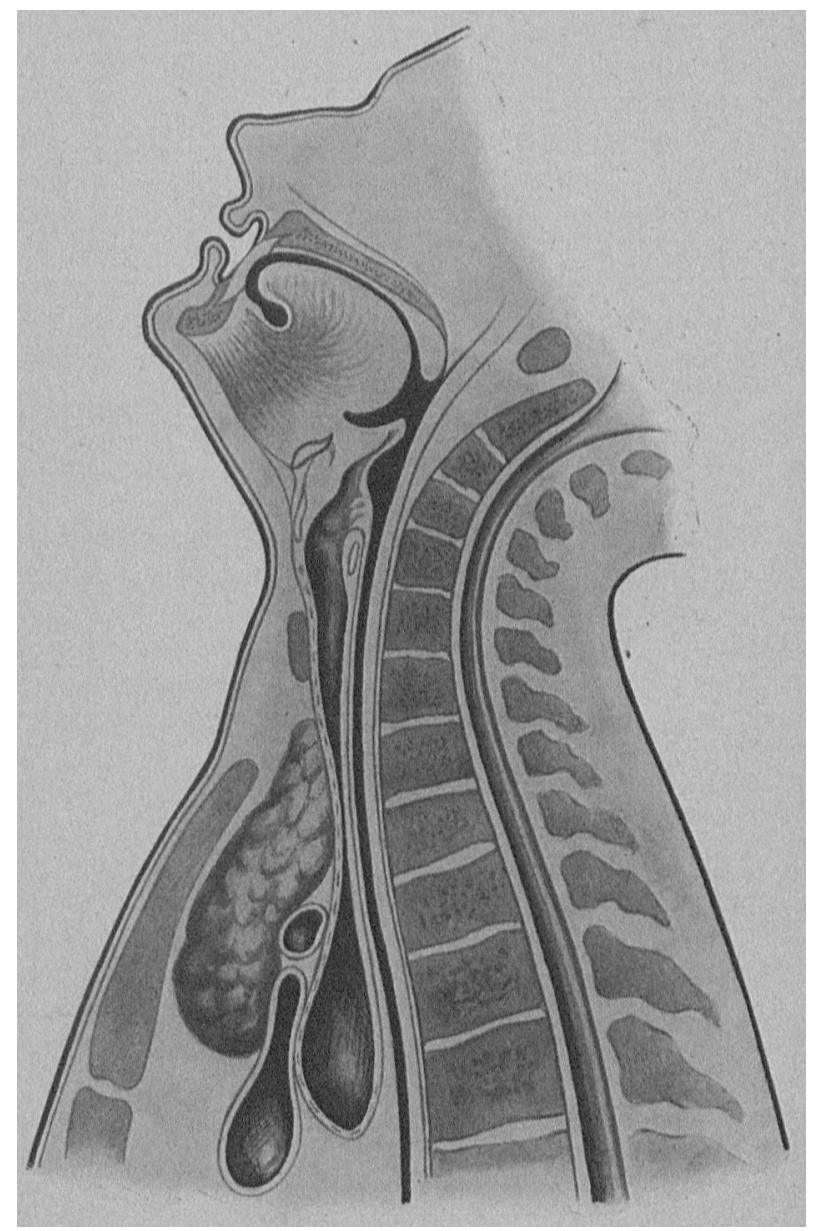

Fig. 6.-Ilyperextension of the hend, showing how compression of the trachea by a hyperplastle thymus chn take place. The cervical certebrae are displined forward; the larynx and mediastinal organs are ralsed upward; the thymus is caught llke a wedge between the sternam and spinal cclumn. Hence compression of windplpe (Klose).

trunk and the left common carotid (Fig. 4); hence cyanotic symptoms characterized by distention of the veins of the neck, the puffiness of both supraclavicular spaces, cyanosis of the face and distention of the large fontanelle. During paroxysms these symptoms become extremely marked. The veins of the neck are much distended and the fontanelle protrudes; the face is puffed and the child is in a semi-comatose condition. The heart beats violently, or in certuin cases stops beating. When the paroxysm is over, these symptoms retrocede, but in other cases it terminates in deatl. Autopsy shows that compression of the right auricle and ventricle and of the superior vena cava and aorta is very marked. In such 
cases the dyspneic symptoms are of secondary importance. The vascular srmptoms dominate the scene and extreme repletion of the veins of the neck and face, distention of the large fontanelle and the tendency to collapse will differentiate this form of cyanosis from the one due to congenital malformations of the heart. In the persistence of the foramen ovale, the cranotic condition of the patient is uniformly distributed and persistent.

In people who die suddenly, autopsy does not always show the cause of death. In such cases, especially in children and young adults, the thymus is found enlarged. It is the only finding. If the thymus compresses the trachea and the large vessels, dyspnea and cyanosis will be found in the history of the case, and the autopsy will revenl that there is a compression of the windpipe and of the large vessels by an enlarged thymus. In such cases, even when the paroxysms have been short and unique, the cause of death is easily found,' and its relation to the enlargement of the thymus is seen. But besides these, there are other cases of sudden death, in which no causes at all are revealed. There is no dyspnea, no cyanosis. The thymus is enlarged, but there is no sign of compression anywhere. Such deaths occur under anesthesia, and it makes no difference what anesthetic is used or in what amount. Death occurs early in the process of anesthesia or even after the patient has recovered from the anesthetic. In such cases, as a rule, the patient during anesthesia shows a tremor which resembles shivering from cold, as in my Cases 2 and 6. The respiration is accelerated and superficial; the pulse is weak; the face is white; the pupils are dilated; respiration stops first and then the heart.

Death during anesthesia for operation for adenoids Ims been thought to be due to a thymus enlargement, which in such cases coincides with the enlargement of the tonsils, adenoids and other lymphoid tissues-in other words, with a status thymolymphaticus. Sudden death may occur in little children, especially during the night. The child wakes up suddenly, tries to stand up, his pupils become dilated, his respiration stops, he stiffens and contracts himself and dies. This death has been reported, too, after plunging the child into cold water, after the opening of a retropharyngeal abscess, after \& simple examination of the throat and after a simple hyperextension of the head.

Hyperplasia of the thymus has been found in connection with alterations of the endocrines glands, in simple goiter, hyperthyroidism and myxedema, acromegaly and tetany 'In goitrous countries, especially in Bernese regions, where goiter is endemic, thymus hypertrophy and struma in the new-born is exceedingly frequent. In 1910, in the Bernese Pathologic Institute, forty-four post-mortems of the new-borr were made. In twelve of these cases thymus hyperplasia was extremely marked and the goiter of large size. In adults this combination of thymus hyperplasia and goiter is more frequent than it lias heretotore been supposed.

Rössle reports a series of fifty-two cases of hyperthyroidism with thymus hyperplasia. McCardi, in thirtyfive cases of sudden death in hyperthyroidism, found eighteen cases with hyperplasia. Rehn, in 319 cases of Graves' disense, treated surgically, had forty-two deaths. Six patients died with extremely marked dyspneic symptoms. In the literature Matti found 1333 cases of hyper. thvroidism, in which post-mortem had been held, and in ninety-cight cases, making 74 per cent. of the total cases, hyperplastic thymus was found. These figures show that thymus hyperplasia, in combination with Graves' discase, is very trequent.

In many such cases death has been mechanically duc to a compression of the windpipe or to a stretching of the inferior laryngeal nerve, but in a great many other cases death ean occur without compression or iritation of the laryngeal nerve, and no dyspneic symptoms are present. In such cases the explanation of sudden death by compression of the large vessels and trachea would not be correct. Some have thought that death was due to compression of the phrenic nerves, hence apnea; others have thought that death was due to pressure of the vagus and inferior cardiac nerve, hence collapse; but there are no anatomic facts to substantiate these theories. When compression on the base of the heart is very marked, as in my Case 3, I believe that deatl may be due to a compression of the heart's ganglions.

Paltauf explains such death by his lymphaticothymic theory. In his judgment, thymus hyperplasia is only one symptom among others of a disease which involves the entire lymphatic apparatus, and which he calls status thymolymphaticus. This condition would cause abnormal metabolic changes, which take place in the nervous centers controlling the heart action and cause a sudden cardiac insufficiency with acute dilatation of the heart. This hypothesis, possibly correct in a few cases, has not been sufficiently corroborated by facts, and does not stand the analysis of our new anatomic and physiologic acquisitions. The thymus is not a lymphoid, but a glandular organ. Cases of pure thymus hyperplasia, without status lympluaticus, and vice versa, are often found, and in many cases of thymus hyperplasia with sudden death the syndrome of Paltauf is lacking:

I ately Svehla has asserted that the thymus gives off an internal secretion, and he thinks that death is due to this substance acting on the heart and the nervous system.

In injecting a watery solution of thymus extract into animals, Svehla found a diminution in the bloodpressure and increased rapidity of the pulse. Repeated injections caused death of the animals; therefore he considers the mors thymica a consequence of a hyperthymization, which causes a diminution in the bloodpressure.

Vincent, Hart, Sheen, Farini and Vidoni confirmed these findings, but found that other extracts of tissues, muscles, kidney, liver, testicles, spleen, pancreas and lungs have the same depressive effect on the heart; these observers concluded that this property of diminishing the blood-pressure is not specific to the thymus.

The physiologic action of the thymus is not yet clear. This organ must certainly be of importance to the organism, because it grows until the age of puberty and then gradually retrocedes, but remains of it are still found in old age. According to the latest experiments of Klose, this organ is essential to life. Congenital absence of the thymus has been found in a few cases, but only in the new-born who died from other causes, so that they did not live long enough to show the pathologic effects of an absence of the thymus. Tubarsch performed an autopsy on an infant 8 weeks old, in which the absence of the thyroid was total. A careful examination of the other glands, thyroid, hypophysis, adrenals, pancreas and genital organs did not reveal any detectable pathologic conditions.

The results of the transplantation of thymus are contradictory, and it may be said in conclusion that the transplaniting of a normal thymus does not cause any 
symptoms, lut that the transplanting of a hyperplastic or pathologic thymus causes toxic symptoms which center their effect especially on the circulatory and nervous apparatus. In my Case 3, I had marked thymotoxic symptoms; in Case 4, no symptoms at all.

Bircher, after implanting in the peritoneal cavity of dogs a fresh hyperplastic thymus taken from a patient who died alter an operation for Graves' disease, observed marked cardiuc and nervous symptoms, a hyperplasia of the thyroid gland and an exophthalmos. Schmidt and other authors in doing the sume experiment obtained negative results.

How is death after strumectomy in hypertlyyoidism to be explained? In order to give a satisfactory answer, we should know a little more about the relations between the thyroid and the thymus. Do they have an antagonistic action or do they work harmoniously? Gierke believes that the two glands compensate each other more or less and that in strumectomy there is a diminution in the thyroid sceretion and consequently an increased thymus function, which causes a hyperthymization.

Rössle thinks that the hypertrophy is only an expression of the increased demand in the function of an organ; possibly in Graves' disease the hypertrophy of the thyroid is not sufficient to furnish the desired amount or quality of secretion. Therefore the thymus hypestrophies in order to supply the deficiency of the thyroid.

Hart thinks that there is an antagonism between the functions of the thymus and the thyroid. He believes that the hyperplasia of the thyroid is due to the effort of this gland to destroy the poisons of thymic origin. Sudden death after strumectomy in hyperthyroidism is due, according to Hart, to a thymic auto-intoxication.

Garre, Capelle and Bier believe that the thymus aggravates the hyperthyroid symptoms. The thymus, in their judgment, does not compensate the thyroid secretion, but works more or less harmoniously with the thyroid; the thymus, like the thyroid, has a sympatheticotonic and vagotonic action.

Bircher believes in the possibility of a hyperthyroidism of thymic origin and thinks that the thyroid and the thymus have an antagonistic action.

From all these different opinions, we can draw the conclusion that the hyperplastic thymus aggravates Graves' disease, but we do not yet know the exact relation between the thymus and the thyroid. The solution of the problem is still a difficult one and will be solved probably when we know a little more about the internal secretion and the part played by the hormones.

Wiesel and Hedinger found in cases of status thymolymphaticus a hyperplasia of the chromaffin system, and Matti found experimentally that after thymęctomy the medullary substance of the adrenal bodies is markedly increased and that in cases of thymus hyperplasia the medullary substance of the adrenals was decidedly diminished. Hence the conclusion of Wiesel that in cases of status thymicus there is a hypoplasia of the chromaffin system. In that case the secretions of these bodies, which in normal condition have a tonic action on the vascular system, are diminished or wanting; hence hypotony, a diminution in the blood-pressure, and finally a paralysis of the vascular and cardiac systems and death. This explanation is not in accordance with my researches. I have made it a practice to determine the epinephrin content of the blood in every goiter case. In hyperthyroidism I have found, as a rule, an increased epinephrin content in the blood. The whole question is far from being solved and needs further investigation.

151 East Broad strect.

\section{BOIIJE VERSUS RAW MILK}

AN JEPEIIIMIENTA STUDY OF MILK COAGULATION IN TIIL STOMACH, TOGETHER WITII CLINICAL OBSERVATIONS ON THE USE OF RAW AND BOHLED MHLK

\section{JOSEPH BRENNEMANN, M.D.} CHICAGo

Milk, alone of all foods, enters the stomach a liquid and becomes there a more solid food. This hidden and insidious solidness, if I may use the term, is peculiarly characteristic of raw cow's milk, as compared with boiled cow's milk, or humnan milk. The housewife and the dairyman are practically familiar with the fact that boiled milk forms a different curd from raw milk. We, on the other hand, have quite ignored the fuct that raw and boiled milk are not identical foods. If we have thought of it at all it has been rather from a bacteriologic than from a physiologic point of view. And yet boiled cow's milk forms in the stomach, as does humian milk, nearly a liquid food; while raw cow's milk, as I shall hope to demonstrate, is not even a soft food, but a solid food, so solid, in fact, that, unless modified in some way and given in careful moderation, it commonly forms hard masses that pass undigested throughout the whole alimentary tract and appear as hard curds in the stools.

It is exactly in these liard curds that one has the most tangible evidence that raw and boiled milk are not interchangeable clinical and experimental factors. It will be remembered that Talbot' demonstrated from various angles that these "hard tough curds" were casein derivatives, that is, "casein curds," in contradistinction to the small, soft, white curds that are "fat curds." Meyer and Leopold, ${ }^{2}$ representing the Finkelstein school, denied the existence of a casein curd, basing their conclusions on the analysis they had made and on metabolism experiments. There was only one possible explanation for this discrepancy between equally competent observers about so simple a phenomenon; the hard curds that Talbot and other American clinicians described did not occur in Leopold and Meyer's experience. 'Talbot used raw milk, Meyer and Leopold used boiled milk exclusively, and the hard curd is essentially a raw-milk phenomenon, as pointed out independently by Ibrahim? and myself." Meyer then fed a number of babies raw milk and promptly for the first time in his enormous experience saw these hard curds, and at once granted their casein origin. After being impressed again and again by the striking differences in the behavior of raw milk and boiled milk, first in the clinic and then in laboratory and stomach experiments, I cannot help feeling that other differences in clinical results will be cleared up, as in this case, if we have in mind that raw milk and boiled milk are not identical foods.

In the former paper I offered as an explanation, as did also Ibrahim, 3 for the invariable occurrence of these hard curds when enough raw milk was fed, that, while

1. 'Talbot, F. 13. : Composition of Largo Curds In Infants' Stools, Isoston Med. and Surg. Jour.. June 11. 1008, p. 205: The Compo. Ition of Snatl Curds of Infants Stools, Loston Mfed. and Surg. our., Jan. 7, 1009, p. 13; Caseln ('urds of Infunts' Stoo!s, . 1 rech. Biologic Proof of 'J'beir Casein Orlgín. Irell. Indlat., June, 1010. 1). 440 .

440. Meyer, I. J., and leopold, .J. S.: The So-Called caseln Masses in Infunts' Stools, Arell. l'ediut., October, 1009, p. Ti3, and February, 1910, p. 126.

3. Ibrahim. J.: Kascinklumpen tm Kinderstuhl in Zusammen. hang mit Robmilchornihrung, Monntscirr. f. Kinderh., 1011, $x$ No. 2 .

Bronnominn. Joscup : A Contribution to Our Knowledge of the Etlology and Nituro of IIard curds In Infants' Stools, Am. Jour. Dis. Child., May, 1911, p. 341 . 